\title{
Role of Color Doppler Ultrasonography in Differentiation of Graves' Disease from Thyroiditis: A Prospective Study
}

\author{
${ }^{1} \mathrm{KS}$ Thalavai Sundarram, ${ }^{2}$ Dhalapathy Sadacharan, ${ }^{3} \mathrm{Krishnan}$ Ravikumar, ${ }^{4} \mathrm{~S}$ Kalpana, ${ }^{5} \mathrm{RV}$ Suresh
}

\begin{abstract}
Introduction: Thyrotoxicosis due to Graves' disease (GD) and destructive thyroiditis (DT) needs differentiation, as management strategy differs. Factors that help in diagnosis are biochemical and nuclear imaging. Utility of high-resolution ultrasonography (HRUSG) and color Doppler (CD) in differentiation is not widely practiced. We undertook the prospective study in the Department of Endocrine Surgery at a tertiary care center among South Indian population in 1 year as a cost-effective model
\end{abstract}

Materials and methods: Out of 120 newly diagnosed thyrotoxicosis patients, 54 were GD (group I) and 66 were DT (group II) patients. Totally, 55 euthyroid patients served as controls. Parameters analyzed were demography, free thyroid function test (TFT) anti-thyroid-stimulating hormone receptor antibody (TSHrAB), antithyroid peroxidase antibody (ATPO), anti-thyroglobulin antibody (ATG), and Tc-99m thyroid scintigraphy. Parameters analyzed using HRUSG and CD were peak systolic velocity (PSV), end-diastolic volume (EDV), pulsatility index $(\mathrm{PI})$, resistive index $(\mathrm{RI})$ of bilateral superior thyroid artery (STA) and inferior thyroid artery (ITA).

Results: Both groups were age and sex matched. The TFT, ATPO, and ATG were comparable between both groups $(p=0.609)$. The TSHrAB $(\mathrm{IU} / \mathrm{mL})$ was significantly higher in group I $(36.11 \pm 0.82)$ than group II $(1.23 \pm 0.24)(p<0.001)$. Mean thyroid volume $(\mathrm{mL})$ was higher in group I $(28.9 \pm$ $14.9)$ than group II $(26.2 \pm 8.81)(p=0.022)$. Mean PSV-STA $(\mathrm{cm} / \mathrm{s})$ was statistically higher in group I $(54.09 \pm 4.67)$ than group II $(28.92 \pm 4.39)(p \leq 0.001)$. Mean PSV-ITA $(\mathrm{cm} / \mathrm{s})$ was higher in group I $(32.11 \pm 2.45)$ than group II $(25.23 \pm 3.45)$ $(p=0.006)$. Other parameters measured in both arteries like mean EDV $(\mathrm{cm} / \mathrm{s})$, mean $\mathrm{RI}$, and mean $\mathrm{PI}$ were comparable between both groups.

\footnotetext{
${ }^{1}$ Resident, ${ }^{2}$ Associate Professor, ${ }^{3}$ Assistant Professor, ${ }^{4}$ Professor ${ }^{5}$ Professor and Head

1,2,5 Department of Endocrine Surgery, Rajiv Gandhi Government General Hospital, Madras Medical College, Chennai, Tamil Nadu, India

${ }^{3}$ Department of Endocrine Surgery, Christian Medical College Vellore, Tamil Nadu, India

${ }^{4}$ Barnard Institute of Radiology, Rajiv Gandhi Government General Hospital, Madras Medical College, Chennai, Tamil Nadu, India

Corresponding Author: KS Thalavai Sundarram, Resident Department of Endocrine Surgery, Rajiv Gandhi Government General Hospital, Madras Medical College, Chennai, Tamil Nadu, India, Phone: +919894639539, e-mail: drthalavai@ gmail.com
}

Conclusion: The HRUSG with CD evaluation of PSV STA and ITA is a cost-effective alternative to TSHrAB and thyroid scintigraphy in differentiating GD from DT patients. Additionally, we observed that PSV in STA was higher than in ITA in patients with GD. To conclude, HRUSG and CD are simple, cost-effective, and widely available tools in the differentiation of GD from DT.

Keywords: Color doppler ultrasonography, Destructive thyroiditis, Graves' disease, Peak systolic velocity, Superior thyroid artery, Thyroid blood flow.

How to cite this article: Sundarram KST, Sadacharan D, Ravikumar K, Kalpana S, Suresh RV. Role of Color Doppler Ultrasonography in Differentiation of Graves' Disease from Thyroiditis: A Prospective Study. World J Endoc Surg 2017; 9(2):41-45.

\section{Source of support: Nil}

Conflict of interest: None

\section{INTRODUCTION}

The management of hyperthyroidism depends upon the differentiation of two of its common etiology, i.e., Graves' disease (GD) and destructive thyroiditis (DT), and may cause a diagnostic dilemma in a few cases. In GD, thyrotoxicosis is due to the hyperfunctioning of thyroid gland, whereas in DT, destruction of gland leads to excess release of the stored thyroid hormones. Thyroid scintigraphy is a gold standard tool in differentiating the etiology of hyperthyroidism, but it is not widely available and not cost-effective. In GD, the modalities of treatment advocated include antithyroid drugs, radioactive iodine, and surgery, but in thyroiditis, symptomatic relief with anti-inflammatory agents and beta-blockers constitutes the first line of management. Elucidating the diagnosis is of paramount importance in categorizing hyperthyroidism with regard to GD and DT.

High-resolution ultrasonography (HRUSG) with CD is a widely available, cost-effective tool employed in all cases of hyperthyroidism. Various parameters can be analyzed by HRUSG with CD in addition to the routinely measured sonographic details of the thyroid. Blood flow in GD is usually so high that the peak systolic velocity (PSV) in thyroid arteries can reach up to a mean of $100 \mathrm{~cm} / \mathrm{s}$ more than the reported normal mean thyroid artery PSV, which is 15 to $30 \mathrm{~cm} / \mathrm{s}$, and it would vary from thyroiditis. ${ }^{1}$ The major source of blood supply to the thyroid gland is by 
the superior thyroid artery (STA) and inferior thyroid artery (ITA); STA, being the first direct branch of external carotid artery, has a preponderance of blood supply to the thyroid parenchyma compared with the ITA, which is a branch of thyrocervical trunk arising from the subclavian artery. This increased vascularity in GD is exploited in our study to evaluate the dynamics of blood flow with regard to thyrotoxicosis. ${ }^{1-3}$

The HRUSG with CD is a technology used for quantitative and qualitative measurement of vascularity in the thyroid gland. It records the blood flow velocity using color encoding images, which is superimposed on the gray-scale image. The condition of parenchymal blood flow is an important indicator of thyroid status. For quantitative Doppler evaluation, the PSV (the Doppler waveform recorded at the point with the highest frequency shift) was used, which permits the analysis of velocity and spectral parameters of the blood flow as well as the calculation of some indices.

Markova et al suggested the following values as normal blood flow parameters. Mean PSV in STA was $16.8 \pm 0.94 \mathrm{~cm} / \mathrm{s}$ and in the ITA it was $15.8 \pm 0.77 \mathrm{~cm} / \mathrm{s}$. The mean end-diastolic volume (EDV) in STA is $7 \pm 1.2 \mathrm{~cm} / \mathrm{s}$ and in ITA is $6.36 \pm 0.29 \mathrm{~cm} / \mathrm{s}$. The resistive index (RI) in STA is $0.56 \pm 0.01$ and in ITA is $0.58 \pm 0.01 .^{4}$ Struchkova et al also suggested the following parameters as the nominal blood flow in thyroid arteries: PSV $10.4 \pm 28.1$ $\mathrm{cm} / \mathrm{s}$, EDV $3.1 \pm 9.6 \mathrm{~cm} / \mathrm{s}$, RI $0.5 \pm 0.75$, and pulsatility index $(\mathrm{PI}) 0.72 \pm 1.2 .^{5}$

\section{MATERIALS AND METHODS}

This prospective study was done in the Department of Endocrine Surgery, Madras Medical College, Chennai, India, a tertiary care referral center in South India over a 1-year period from August 2015 to July 2016. Patients' informed consent and Institutional Ethical Committee approval were obtained for this study.

Newly diagnosed hyperthyroid patients exhibiting features of thyrotoxicosis with biochemically elevated free triiodothyronine (FT3) and free thyroxine (FT4) and suppressed thyroid-stimulating hormone (TSH) values (normal range TSH: 0.5-5.0 $\mu \mathrm{IU} / \mathrm{mL}, \mathrm{FT4}$ : 0.82-1.51 ng/dL, FT3: $1.95-5.4 \mathrm{pg} / \mathrm{mL}$ ) were included as study cohorts. The study cohorts were classified into two groups based on the scintigraphic findings performed using (Tc-99m) technetium pertechnetate. Group I comprised GD showing diffuse increased uptake, and patients with low or no uptake were categorized as DT in group II. Totally, 120 patients were eligible and included in this study based on the above-said criteria. Of these 120 patients, 54 patients were in group I and the remaining 66 cohorts in group II. A total of 55 age- and sex-matched euthyroid patients were included in the study to serve as controls.
The basic parameters analyzed include demography, serum anti-TSH receptor antibody levels (TSHrAB) measured using electrochemiluminescence immunoassay (normal range $<1.8 \mathrm{IU} / \mathrm{L}$ ), antithyroid peroxidase (ATPO) antibody (normal value is $<2 \mathrm{IU} / \mathrm{mL}$ ), antithyroglobulin antibody (ATG, normal value is $<7 \mathrm{IU} / \mathrm{mL}$ ) both measured by enzyme-linked fluorescent assay. High-resolution ultrasonography with CD (Siemens Acuson Antares Premium Edition) with a 15-MHz linear transducer was used to analyze various parameters.

Using HRUSG with CD, various parameters like mean PSV, EDV, PI, RI of STA and ITA on both sides were evaluated by a single sonologist who was blinded to the biochemical and scintigraphic details. The thyroid volume was also calculated using the formula length $x$ width $\times$ depth $\times 0.479$.

The HRUSG with CD evaluation of thyroid arteries measurement was done in 1-mm sample volume adjustment in vessel center with the insonation angle kept $0^{\circ}$ to $60^{\circ}$ and correction angle adjusted parallel to the vessel wall. ${ }^{6}$ Transducer pressure over skin was minimum, with appropriate transducer and equipment adjustment; velocity scale was maintained with values $\leq 5.0 \mathrm{~cm} / \mathrm{s}$. The PSV and indices were measured in the ITA and STA.

Data were analyzed using Statistical Package for the Social Sciences software (IBM SPSS Statistics 21.0; SPSS Inc, Chicago, Illinois). For comparison of continuous variables between different groups, Student's t-test was used. Categorical data analysis was done using Chi-square test. Data from each group were expressed as mean \pm standard deviation. The $\mathrm{p}$-value of $<0.05$ was considered significant statistically.

\section{RESULTS}

Of the 120 study cohorts in both the groups, predominantly 109 (91\%) were females and $11(9 \%)$ were males, and $85 \%$ of the control group were females. The cohorts in the study groups were age and sex matched $(p=0.205)$. The mean age in group I was $40.9 \pm 12.5$ years and in group II, it was $38.0 \pm 10.1(p=0.806)$. The mean age of the control euthyroid patients was $36.7 \pm 09.5$ years.

The mean FT4 (ng/dL) value in group I was $8.86 \pm 1.14$, which was nonstatistically higher than the mean value in group II, $6.42 \pm 1.65$ ( $p=0.061$ ). The mean serum TSH $(\mu \mathrm{IU} / \mathrm{mL})$ in group I was $0.02 \pm 0.04$ and it was $0.04 \pm 0.32$ in group II ( $\mathrm{p}=0.120)$. The TSHrAB (IU/L) levels were elevated in 52/54 (96.3\%) of group I cohorts measuring $36.11 \pm 0.82$, whereas only $5 / 66(7.57 \%)$ patients in group II had higher TSHrAB levels, with a mean value of $1.23 \pm$ 0.24 ( $p<0.001)$. The ATPO antibody $(\mathrm{IU} / \mathrm{mL})$ levels were elevated in $44 / 54(81.8 \%)$ of group I patients measuring $428.2 \pm 100.86$ and 59/66 (89.39\%) patients in group II, 


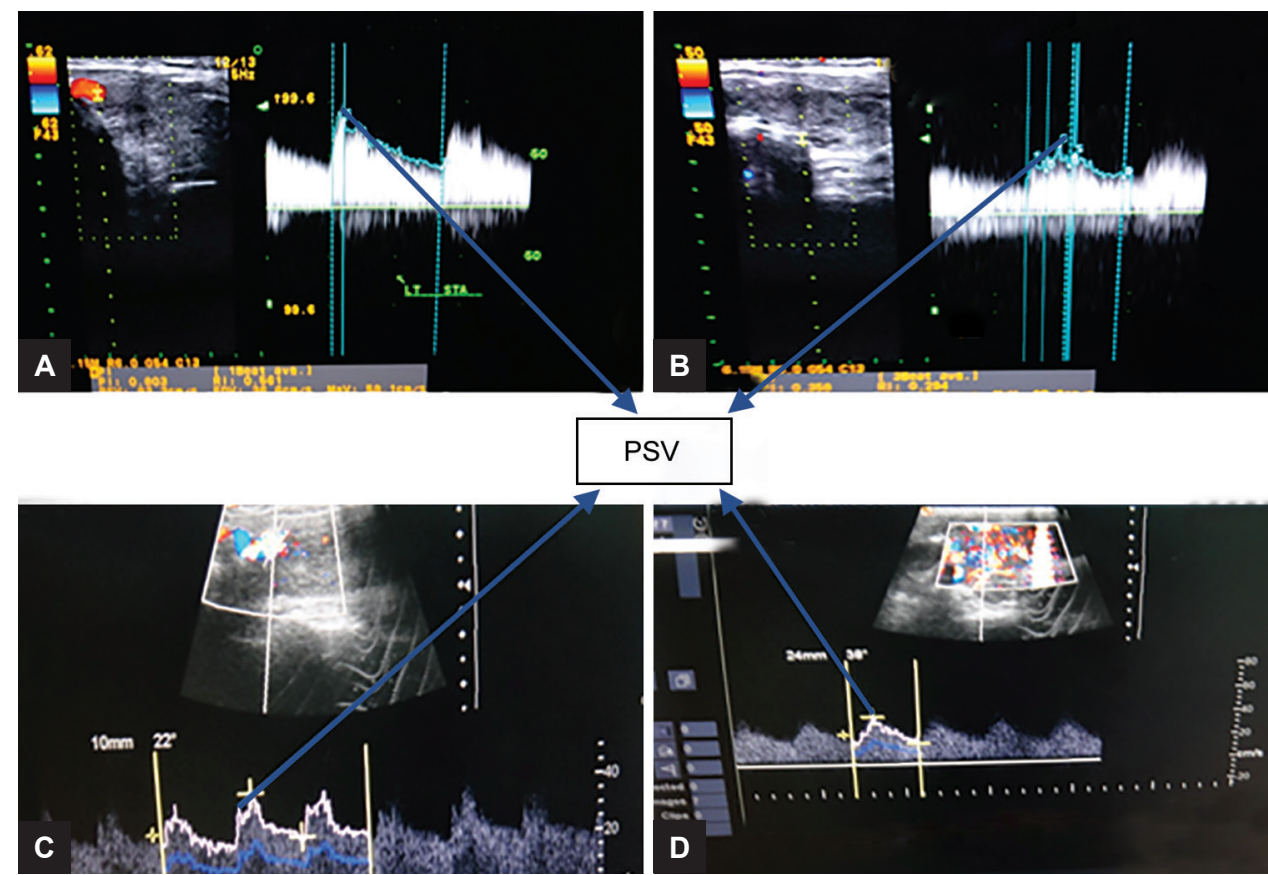

Figs 1A to D: (A) Color Doppler PSV (STA) in group I; (B) Color Doppler PSV (STA) in group II; (C) Color Doppler PSV (ITA) in group I; and (D) Color Doppler PSV (ITA) in group II

with a mean value of $510.9 \pm 200.72(\mathrm{p}=0.095)$. The ATG (IU/mL) levels were elevated in 41/54 (75.92\%) patients in group I with a mean value of $654.7 \pm 102.98$ and 53/66 $(80.30 \%)$ in group II with a mean measurement of 550.3 \pm 104.27 ( $\mathrm{p}=0.083)$.

The mean thyroid volume $(\mathrm{mL})$ in group I was $(28.9 \pm$ 14.9) comparable to group II patients $(26.2 \pm 8.81)(\mathrm{p}=1.324)$. The mean thyroid volume in the control group was 8.97 $\pm 5.27 \mathrm{~mL}$.

The mean PSV-STA $(\mathrm{cm} / \mathrm{s})$ in group I was $54.09 \pm 4.67$ and in group II, it was $28.92 \pm 4.39$. The PSV-STA in group I (Fig. 1A) was statistically significant than in group II(Fig. 1B) $(\mathrm{p} \leq 0.001)$. The PSV-STA in control group was $14.3 \pm$ $0.92 \mathrm{~cm} / \mathrm{s}$. The mean PSV-ITA (cm/s) in group I (Fig. 1C) was $32.11 \pm 2.45 \mathrm{~cm} / \mathrm{s}$ and in group II (Fig. 1D) it was 25.23 $\pm 3.45 \mathrm{~cm} / \mathrm{s}(\mathrm{p}=0.006)$. The PSV-ITA in control group was $11.2 \pm 0.68 \mathrm{~cm} / \mathrm{s}$. The bilateral mean EDV-STA $(\mathrm{cm} / \mathrm{s})$ in group I was $22.15 \pm 2.45$ and in group II was $18.12 \pm 3.55$ $(\mathrm{p}=0.098)$. The EDV-STA was nonsignificantly higher in group I than in group II. The EDV-STA in control group was $07.72 \pm 4.68 \mathrm{~cm} / \mathrm{s}$.

The bilateral mean EDV-ITA $(\mathrm{cm} / \mathrm{s})$ in group I was $17.11 \pm 2.05$ and group II was $15.13 \pm 1.49(p=0.067)$. The EDV-ITA was nonsignificantly higher in group I than group II. The EDV-ITA in control group was $06.372 \pm 2.38$ $\mathrm{cm} / \mathrm{s}$. The bilateral mean RI-STA in group I $(0.79 \pm 0.18)$ was not statistically higher than in group II $(0.67 \pm 0.12)$ $(\mathrm{p}=0.863)$. The RI-STA in control group was $0.52 \pm 1.08$. The bilateral mean RI-ITA in group I $(0.69 \pm 0.15)$ was not statistically higher than in group II $(0.60 \pm 0.08)(\mathrm{p}=0.091)$. The RI-ITA in control group was $0.49 \pm 04.68$.
Table 1: Comparison of parameters between study groups

\begin{tabular}{|c|c|c|c|}
\hline Parameters & $\begin{array}{l}\text { Group I GD } \\
(n=54)\end{array}$ & $\begin{array}{l}\text { Group II DT } \\
(n=66)\end{array}$ & $p$-value \\
\hline Age (years) & $40.89 \pm 12.45$ & $38.00 \pm 10.11$ & 0.086 \\
\hline $\operatorname{Sex}(M: F)$ & $5: 49$ & $6: 60$ & 0.205 \\
\hline FT4 (ng/dL) & $8.86 \pm 1.14$ & $6.42 \pm 1.65$ & 0.061 \\
\hline TSH $(\mu \mathrm{IU} / \mathrm{mL})$ & $0.02 \pm 0.04$ & $0.04 \pm 0.32$ & 0.120 \\
\hline ATPO (IU/mL) & $428.2 \pm 100.86$ & $510.9 \pm 200.72$ & 0.095 \\
\hline ATG $(\mathrm{IU} / \mathrm{mL})$ & $654.7 \pm 102.98$ & $550.3 \pm 104.27$ & 0.083 \\
\hline TSHrAB (IU/mL) & $36.11 \pm 0.82$ & $1.23 \pm 0.24$ & $<0.001$ \\
\hline PSV-STA (cm/s) & $54.09 \pm 4.67$ & $28.92 \pm 4.39$ & $<0.001$ \\
\hline PSV-ITA $(\mathrm{cm} / \mathrm{s})$ & $32.11 \pm 2.45$ & $25.23 \pm 3.45$ & 0.006 \\
\hline EDV-STA (cm/s) & $22.15 \pm 2.45$ & $18.12 \pm 3.55$ & 0.098 \\
\hline EDV-ITA $(\mathrm{cm} / \mathrm{s})$ & $17.11 \pm 2.05$ & $15.13 \pm 1.49$ & 0.067 \\
\hline RI-STA & $0.59 \pm 0.18$ & $0.57 \pm 0.12$ & 0.863 \\
\hline RI-ITA & $0.60 \pm 0.08$ & $0.69 \pm 0.15$ & 0.091 \\
\hline PI-STA & $1.95 \pm 0.33$ & $1.87 \pm 0.43$ & 0.576 \\
\hline PI-ITA & $1.01 \pm 0.18$ & $0.96 \pm 0.0 .5$ & 0.565 \\
\hline
\end{tabular}

Values $=$ mean \pm standard deviation

The bilateral mean PI-STA in group I $(1.95 \pm 0.33)$ was not statistically higher than in group II $(1.87 \pm 0.43)$ $(\mathrm{p}=0.576)$. The PI-STA in control group was $0.89 \pm 0.18$. The bilateral mean PI-ITA in group I $(1.01 \pm 0.18)$ was not statistically higher than in group II $(0.96 \pm 0.0 .5)$. ( $\mathrm{p}=$ $0.565)$. The PI-ITA in control group was $0.79 \pm 0.25$.

The comparison of various parameters between the two study groups is documented in Table 1.

\section{DISCUSSION}

Our study has demonstrated the utility of HRUSG combined with $\mathrm{CD}$ in the evaluation of the most common forms 
of hyperthyroidism in a simpler and cost-effective way, negating the use of scintigraphy in selected patients. The major concern for the clinician in the outpatient setting would be to distinguish GD from DT in a thyrotoxic patient. Graves' disease though has its unique features of ophthalmopathy and other skin changes, there are certain overlapping signs and symptoms in both the entities. An HRUSG with CD is widely available and is increasingly used by thyroid specialists in their outpatient setting. Thus, surgeons performing USG examination will be an extension of clinical evaluation in the outpatient department with the results available immediately for choosing the management strategy.,

Ralls et $\mathrm{al}^{9}$ in 1987 used CD in Graves' patients to show the increased blood flow in the thyroid gland. They coined the term thyroid inferno, indicating diffuse increase in thyroid parenchyma vascularization. Since then, CD has been used to investigate the pathogenesis of thyrotoxicosis. Increased thyroid parenchyma vascularization can also occur in thyroiditis, but to a lesser level. The thyroid parenchyma vascularization correlates with the underlying functional status; it decreases when the disease is under control and can rise again in cases of relapse.

The method used in thyroid HRUSG and CD evaluation is a semiquantitative measurement of the blood flow pattern in the thyroid gland parenchyma, thyroid blood flow pixels per thyroid cross-sectional area, and blood flow velocity in the thyroid artery. ${ }^{10}$ Thyroid CD is a cost-effective, viable alternative available widely, which is noninvasive and radiation free. An HRUSG with CD can be used initially in the differential diagnosis of thyrotoxicosis. ${ }^{11-13}$

In a study by Donkol et al, ${ }^{11}$ the mean PSV of $40.0 \mathrm{~cm} / \mathrm{s}$ in ITA was higher and suggestive of GD, while most other studies proposed a PSV of above $50.0 \mathrm{~cm} / \mathrm{s}$. Values above $100 \mathrm{~cm} / \mathrm{s}$ can be reached in newly diagnosed patients or patients not responsive to treatment. In our study group, the mean PSV in STA in untreated GD patients was 54.09 $\pm 4.67 \mathrm{~cm} / \mathrm{s}$.

In a study by Donkol et al that PSV of ITA was significantly higher in GD than DT patients. An HRUSG with CD demonstrated sensitivity of $88.9 \%$ and specificity of $87.5 \%$, and a positive predictive value of $94.1 \%$, negative predictive value of $77.8 \%$, and diagnostic accuracy of $88.5 \%$, in the differential diagnosis of thyrotoxicosis compared with $99 \mathrm{mTc}$ scintigraphy. ${ }^{11}$

Kumar et $\mathrm{al}^{13}$ in their study reported mean PSV-ITA values of $22.4 \pm 5.4 \mathrm{~cm} / \mathrm{s}$ in DT and $57.6 \pm 13.1 \mathrm{~cm} / \mathrm{s}$ in untreated GD patients. In our study, the PSV-ITA in GD was $32.11 \pm 2.45 \mathrm{~cm} / \mathrm{s}$, whereas PSV-ITA in DT patients was $25.23 \pm 3.45 \mathrm{~cm} / \mathrm{s}$. The reported values were slightly lower than the values in our study subjects, probably due to operator-dependent sites of thyroid artery sampling and racial differences between studies.

In most literatures, it has been observed that vascularity in GD decreased in parallel to the biochemical remission and clinical control, and that HRUSG with CD has the potential to monitor therapy response in patients, as well as distinguish GD patients from DT, with B-mode pattern, without the need for expensive laboratory assays in their studies. ${ }^{9,14,15}$

Vitti et $\mathrm{al}^{15}$ in their study demonstrated that the thyroid parenchymal blood flow can be correlated with the functional state of GD patients, being significantly increased in $17 / 18$ patients with newly diagnosed active hyperthyroidism patients. In patients with DT, the thyroid blood flow did not correlate with the functional state of the gland. ${ }^{16}$

In a study by Macedo et al, ${ }^{16}$ using HRUSG with CD, in 84 healthy iodine-sufficient subjects, the following parameters was proposed as normal: PSV of 24.80 to $25.85 \mathrm{~cm} / \mathrm{s}$ in STA and 20.92 to $21.50 \mathrm{~cm} / \mathrm{s}$ in ITA. In this study, the mean PSV in euthyroid control subjects $(\mathrm{n}=52)$ was $14.3 \pm 0.92 \mathrm{~cm} / \mathrm{s}$ in STA and $11.2 \pm 0.68 \mathrm{~cm} / \mathrm{s}$ in ITA.

The 2011 American Thyroid Association guidelines mentioned HRUSG with CD as a reliable indicator of thyroid blood flow, and that it may have a practical value in the differentiation of cause of thyrotoxicosis, especially in pregnant patients or patients with recent iodine exposure. Its use has also been recommended in special circumstances like amiodarone-induced thyrotoxicosis (AIT) in differentiation of type I AIT from type II AIT. ${ }^{17}$

\section{CONCLUSION}

Our Hospital is owned and operated by the State Government and all the Services are rendered free of cost to the patients. Considering that High resolution ultrasound Machine is a one-time investment with negligible operating cost, including the consumables and a single operator needed to perform color doppler flow assessment.

Were as other investigations such as Thyroid Scintigraphy does have a high operating cost considering strict measures to be adhered when handling the Radioactive material, which is expensive and also has a short shelf life. The man power involved in the process of performing the test is also more. Performing a HRSUG would cost approximately, INR 500, elsewhere but performing a Scintigraphy would cost INR 4000.Hence HRUSG is cost effective when compared to other widely used investigation.

\section{REFERENCES}

1. Chaudhary V, Bano S. Thyroid ultrasound. Indian J Endocr Metab 2013 Mar-Apr;17(2):219-227. 
2. Ota H, Amino N, Morita S, Kobayashi K, Kubota S, Fukata S, Kamiyama N, Miyauchi A. Quantitative measurement of thyroid blood flow for differentiation of painless thyroiditis from Graves' disease. Clin Endocrinol (Oxf) 2007 Jul;67(1): 41-45.

3. Ueda M, Inaba M, Kumeda Y, Nagasaki T, Hiura Y, Tahara H, Onoda N, Ishikawa T, Nishizawa Y. The significance of thyroid blood flow at the inferior thyroid artery as a predictor for early Graves' disease relapse. Clin Endocrinol (Oxf) 2005 Dec;63(6):657-662.

4. Kharchenko, VP.; Kotlyarov, PM.; Mogutov, MS.; Alexandrov, YK.; Sencha, AN.; Patrunov, YN.; Belyaev, DV. Complex ultrasound diagnosis of thyroid diseases. In: Ultrasound diagnostics of thyroid diseases. Berlin Heidelberg: Springer; 2010. p. 19-33.

5. Sergeeva ED, Bazarbaev VA. Modern technologies of ultrasound examination in diagnosis of thyroid disease. N Engl J Med 2000 Oct;343(17):1236-1248.

6. Bogazzi F, Bartalena L, Brogioni S, Mazzeo S, Vitti P, Burelli A, Bartolozzi C, Martino E. Color flow Doppler sonography rapidly differentiates type I and type II amiodarone-induced thyrotoxicosis. Thyroid 1997 Aug;7(4):541-545.

7. dos Santos TARR, Pina ROG, de Souza MTP, Chammas MC. Review article: Graves' disease thyroid color-flow Doppler ultrasonography assessment. Health 2014 Jun; 6(12):1487-1496.

8. Chen L, Zhao X, Liu H, Wang Y, Li L, Lu B, Hu R. Mean peak systolic velocity of the superior thyroid artery is correlated with radioactive iodine uptake in untreated thyrotoxicosis. J Int Med Res 2012;40(2):640-647.

9. Ralls PW, Mayekawa DS, Lee KP, Colletti PM, Radin DR, Boswell WD, Halls JM. Color-flow Doppler sonography in Graves' disease: "thyroid inferno". Am J Roentgenol 1988 Apr;150(4):781-784.

10. Hiraiwa T, Hanafusa T. Diagnostic approach to thyroid diseases. Progress in ultrasonography of the thyroid and its application (in Japanese). Nihon Naika Gakkai Zasshi 2010 Apr;99(4):726-732.

11. Donkol RH, Nada AM, Boughattas S. Role of color Doppler in differentiation of Graves' disease and thyroiditis in thyrotoxicosis. World J Radiol 2013 Apr;5(4):178-183.

12. Alzahrani AS, Ceresini G, Aldasouqi SA. Role of ultrasonography in the differential diagnosis of thyrotoxicosis: a noninvasive, cost-effective, and widely available but underutilized diagnostic tool. Endocr Pract 2012 Jul-Aug;18(4): 567-578.

13. Kumar KV, Vamsikrishna P, Verma A, Muthukrishnan J, Rayudu BR, Modi KD. Utility of colour Doppler sonography in patients with Graves' disease. West Indian Med J 2009 Dec;58(6):566-570.

14. Zhao X, Chen L, Li L, Wang Y, Wang Y, Zhou L, Zeng F, Li Y, Hu R, Liu H. Peak systolic velocity of superior thyroid artery, for differential diagnosis of thyrotoxicosis. PLoS One 2012 Nov;7(11):e50051.

15. Vitti P, Rago T, Mazzeo S, Brogioni S, Lampis M, De Liperi A, Bartolozzi C, Pinchera A, Martino E. Thyroid blood flow evaluation by color-flow Doppler sonography distinguishes Graves' disease from Hashimoto's thyroiditis. J Endocrinol Invest 1995 Dec;18(11):857-861.

16. Macedo TA, Chammas MC, Jorge PT, Pereira de Souza L, Farage L, Pegoraro BL, Pessa SU, Cerri GG. Reference values for Doppler ultrasound parameters of the thyroid in a healthy iodine-non-deficient population. Br J Radiol 2007 Aug;80(956):625-630.

17. Bahn RS, Burch HB, Cooper DS, Garber JR, Greenlee MC, Klein I, Laurberg P, McDougall IR, Montori VM, Rivkees SA, et al. Hyperthyroidism and other causes of thyrotoxicosis: management guidelines of the American Thyroid Association and American Association of Clinical Endocrinologists. Thyroid 2011 Jun;21(6):593-646. 